Background Paraquat (dipyridylium herbicide), used commonly in Taiwan, may cause severe pulmonary injury and lung fibrosis and be associated with Parkinsonism. Ocular exposure had caused acute, severe and prolong conjunctivitis with persistent fibrosis, pannus and vascular distortion due to superoxide radicals formation and NADPH depletion via redox cycling reaction as David McKeag's and others' cases. We will report a case with delay onset and relative better prognosis.

Case A 31 years old male farmer had his left eye spilled by Paraquat solution during preparing procedure on Sep 11, 2012. After washing eye by himself with clean water for about 5 minutes, no discomfort was noted initially. Unfortunately, he suffered from pain and tearing 3 days later. Mild conjunctivitis with slight reddish was noted in Ophthalmology Clinic. Focal steroid and antibiotics were used. Progressive worsening condition with more tearing, ocular pain, photophobia, erythematous hyperaemic change, discharge, eyelid swelling, vascular congestion, more papilla and follicles and infiltration had been noted since the $4^{\text {th }}$ day. Eventually, local pulse steroid every day, focal steroid ointment every 2 hours and oral antioxidant were administered on the impression of Paraquat-associated keratoconjunctivitis caused by superoxide radical on $6^{\text {th }}$ day. Pseudomembrane formation was found on $8^{\text {th }}$. Condition was improving after intensive therapy. Symptoms subsided on $12^{\text {th }}$ day and papillae, follicles and infiltration disappeared on $18^{\text {th }}$ day. Only mild dry eye sensation, cicatrization on conjunctiva and no impairment of visual acuity were found 45 days later. No systemic effect could be found.

Conclusion Delay onset is different from acute severe conjunctivitis in McKeag's and other chemical and pesticide exposured ocular injuries. More intense therapy with local pulse steroid and oral antioxidant may improve prognosis with less sequelae. Close monitoring, early management should be considered in case of ocular exposure to Paraquat solution even without early symptom/sign.

\section{INJURY RELATED DEATH OF PRODUCTION WORKER IN SHENZHEN FROM 2007-2011}

${ }^{1} \mathrm{X} J \mathrm{Liu},{ }^{2} \mathrm{Wu},{ }^{2} \mathrm{Fu},{ }^{2}$ Wang, ${ }^{2}$ Cheng. ${ }^{1}$ Shenzhen, China; ${ }^{2}$ Shenzhen Center for Disease Control and Prevention, Shenzhen, China

\subsection{6/oemed-2013-101717.68}

Objectives There are many production workers in Shenzhen, a city of immigrants, which is a public problem, should be concerned. This study aimed to explore the nature of injury related death of production worker, and provided basic interventional measures.

Methods The data were collected from the Death Surveillance System in China from 2007 Jun $1^{\text {st }}$ to 2011 Dec $31^{\text {st }}$. The cause of injury related death was coded from V01 to Y98, and the occupation was production worker. The data were analysed by SPSS 15.0.

Results 517 deaths of production worker due to injury were indentified from 2007-2011 in Shenzhen. There were 437 male workers $(84.5 \%)$, and 80 female workers $(15.5 \%)$. The average age was 34.72. The first five cause of injury death was W17, V03, V09, W20, and V02 (ICD-10, fall and traffic injury), accounted for $15.7 \%, 11.6 \%, 10.6 \%, 7.9 \%$ and $3.9 \%$, respectively. The distribution of injury cause in different district was significant different $(\mathrm{p}<0.05)$.

Conclusions Production worker is a dangerous job. More effective measures should be taken to prevent fall and traffic injury for production worker. The aim population is the young male worker in special district.

\section{BRAZILIAN CONSTRUCTION INDUSTRY: A CONTRIBUTION TO IMPROVE INFORMATION ON FATAL WORK ACCIDENTS}

C A S Salim. Fundacentro/Ministry of Labour and Employment, Belo Horizonte, Brazil

\subsection{6/oemed-2013-101717.69}

Objectives Considering data sources and statistical trends on recent fatal cases resulting from workplace accidents in the Brazilian construction industry, herein two aspects are emphasised: a critical appraisal of the official registers on deaths resulting from work-related accidents, and a discussion on alternatives to achieve better information to support interventions in this sector.

Methods First, statistics and the variability in the profiles of death at work from 2000 to 2010 were analysed for construction industry according to the federal data sources on dimensions related to occupational health, working conditions and social security. Second, besides some difficulties in qualifying of fatal work accidents among the set of external causes of mortality, measurements has been taken in the description of work accidents classified into one of three categories: typical workplace accident; transport accident (that occurring during transport to and from work); work-related diseases.

Results In addition to presentation of specific rates and a set of indicators, a technical proposal is suggested for a more effective and realistic characterisation of the profile of mortality in workplaces by considering age, gender, education, occupation, as well the more frequent causes related to each type of accident. All of them as a condition to understand the main risks and to help teams of OSH facing the worst violence against workers.

Conclusions By reason of the high social and economic costs involving work accidents in Brazil, this study searches to provide a specific comprehension on fatal cases as well as some subsidies for the government to draw policies oriented to minimise risks in the workplaces of construction industry. However, mortality resulting from accidents in the informal labour market should be considered to overcome gap on information. After all, if the number of unemployed workers is underestimated, the number of underemployed has not been taken into account.

\section{IMPROVEMENTS TO SURVEILLANCE OF WORK-RELATED INJURIES IN A DEVELOPING ECONOMY: A CASE STUDY FROM VIETNAM}

${ }^{1} \mathrm{H}$ M W Marucci-Wellman, ${ }^{2}$ Wegman, ${ }^{3}$ Leamon, ${ }^{4}$ Binh, ${ }^{4}$ Diep, ${ }^{2}$ Kriebel. ${ }^{1}$ Hopkinton, United States of America; ${ }^{2}$ University of Massachusetts Lowell, Lowell, United States of America; ${ }^{3}$ Harvard School of Public Health, Boston, United States of America; ${ }^{4}$ National Institute for Occupational and Environmental Health, Hanoi, Vietnam

\subsection{6/oemed-2013-101717.70}

Objectives In Vietnam current public health statistics result in a substantial undercount of injuries and fail to distinguish injuries that occur while working. The objective of this study was to propose incremental changes in reporting to improve surveillance of work-related injuries in this rapidly developing country.

Methods Using nationally published data and the results of our own active surveillance research project in the Xuan Tien 